\title{
Ilse Logie
}

\section{¿Escritos en la traducción y para la traducción? Dos ejemplos: Valeria Luiselli y Mario Bellatin}

\section{Born translated novels}

Según la tesis de Rebecca Walkowitz, formulada en Born Translated. The Contemporary Novel in an Age of World Literature, cada vez más autores contemporáneos escriben obras literarias que nacen "ya traducidas"1; o sea, diseñadas para ser traducidas. En su estudio, Walkowitz examina cómo estas obras imaginan y generan a sus audiencias y cómo cambian la forma tradicional de la novela. Si bien poseen ciertas características que contribuyen a su circulación transnacional, entre otras cosas porque sus autores entienden la traducción como esencia de toda operación literaria o porque ponen en tela de juicio el concepto de originalidad, concibiendo sus textos como copias, versiones o clones, no son necesariamente sinónimo de la estandarización que, según varios estudiosos, sería inherente a la "literatura mundial" 2 . Estos detractores sostienen que, al entrar en el circuito global, los textos literarios son resignificados en términos transnacionales, borrándose sus huellas locales. Para un crítico como Tim Parks, por ejemplo, en Where I'm Reading From, la circulación global y la preocupación por la traducibilidad llevan a una literatura aséptica y homogeneizada (habla de "the dull new global novel"). En la misma línea, el investigador Brian Lennon aboga en In Babel's Shadow. Multilingual Literatures, Monolingual States por obras "no traducibles", o sea, por obras que no se dejen inscribir en esta tendencia. Y, según Vicente Luis Mora, en un dossier de Pasavento dedicado a la globalización en América Latina, empieza a detectarse en la narrativa que nos ocupa en este trabajo, la hispánica, la aparición de lo que

1 La expresión ha sido acuñada por analogía con "born digital", es decir, hecho en la computadora y para la computadora.

2 Entendida aquí de acuerdo a la definición de David Damrosch (4-6): no como un canon de obras, sino como un modelo de circulación y difusión literaria que no se deja reducir a dinámicas de mercado. Damrosch insiste en que, más que un objeto, la literatura mundial es un método de lectura, una manera de comprometerse con la literatura más allá del limitado mundo cultural propio.

Ilse Logie, Universiteit Gent

Ә Open Access. (C) 2020 Ilse Logie, published by De Gruyter. (c) BY-NC-ND This work is licensed under a Creative Commons Attribution-NonCommercial-NoDerivatives 4.0 International License.

https://doi.org/10.1515/9783110673678-012 
llama "panespañol", y que define como "este dialecto literario [que] consist[e] en una especie de castellano estándar mediante el que los escritores van moderando los modismos eliminando las expresiones localistas, para ser más y mejor entendidos, cualquiera que sea el lugar de Hispanoamérica donde sean leídos; especie de lengua posnacional”. Da como ejemplos la prosa de Juan Villoro, Jorge Volpi y Alejandro Zambra. Por su parte, la influyente colección de ensayos compilada por Ignacio M. Sánchez Prado, América Latina en la "literatura mundial", asentó en su día las bases de la recepción generalmente negativa que ha tenido este debate entre los críticos hispanoamericanos.

A Walkowitz esta crítica le parece demasiado simplista. A su modo de ver, las novelas de su corpus obedecen a mecanismos más complejos. Sostiene que las obras de, pongamos por caso, Coetzee o Murakami anticipan distintas culturas literarias al mismo tiempo al dirigirse a través de la traducción a múltiples audiencias locales y no solamente a una única y gran audiencia homogénea ${ }^{3}$. Son textos que no aparecen simplemente "en traducción", sino que incorporan la traducción más que facilitarla. La contienen como condición de producción, como eslabón orgánico en el proceso textual. Walkowitz analiza sobre todo obras escritas en inglés que inventan estrategias para descentralizar esa lengua dotada de elevado capital simbólico a fin de romper su monopolio. Otros ejemplos de autores productores de este tipo de textos que menciona son Teju Cole, Aleksander Hemon, Kazuo Ishiguro, Ben Lerner y -aunque solo aparece aludido- Roberto Bolaño ${ }^{4}$.

En lo que sigue, se presentarán dos textos más recientes con tales características surgidos en el ámbito hispanoamericano: Los ingrávidos (2011), de Valeria Luiselli, y Jacobo el mutante, seguido de su secuela Jacobo reloaded (2002-2014), de Mario Bellatin. Son dos ejemplos que permitirán señalar algunas paradojas que caracterizan esta producción cultural. A pesar de inscribirse en proyectos estéticos divergentes, las obras tienen varios rasgos en común. No solo han sido traducidas a las grandes lenguas internacionales (inglés -que opera como requisito para la inclusión en la literatura mundial-, francés,

3 Walkowitz refuta asimismo el reproche de la falta de compromiso ético o político que se suele achacar a este tipo de obras: "Distance brings neither affective nor ethical detachment [...]. Coetzee rejects both the ideal and the promise: he may be writing for translation, but he is not writing from nowhere; he can't because he associates global invisibility [...] with the very forces he wishes he could disavow" (81).

4 Los detectives salvajes de Bolaño solo es mencionado de paso (17-20) y la inserción del autor en el paradigma de la literatura emergida de la traducción no aparece problematizada, pese a que la obra del chileno se caracteriza por una marcada tensión entre el rechazo del vínculo lengua/territorio por una parte y una tendencia a exhibir el fracaso de lo multilingüe por otra. No sería, por tanto, correcto presentarlo como un representante del discurso de la transparencia en materia de traducción. 
alemán) y han resultado afectadas por este proceso, como veremos a continuación cuando comentemos su afterlife o pervivencia, sino que son libros "ya adaptados", libros que gastan muchas energías escenificando los mecanismos de la escritura y la traducción. Esta última aparece como dispositivo narrativo, al formar parte de la representación que aquellos textos ofrecen de su propia situación enunciativa. Las dos obras proporcionan, asimismo, una reflexión sobre el funcionamiento institucional de la literatura. Son, además, obras globalizadas por varios motivos: por la recepción de la que fueron objeto (sendos autores poseen evidentemente un capital transnacional), pero también por el gesto cosmopolita a través del cual conectan referencias culturales que a primera vista parecen lejanas e incompatibles.

Mi análisis pretende argumentar que Bellatin y Luiselli logran insertarse en este sistema global y hasta adelantarse a la literatura mundial manteniendo una relativa autonomía. Se sostiene en dos ideas: la primera es que la tensión entre lo local y lo mundial constituye el principio generador de sus tramas y que, a través de diferentes procedimientos, logran expandir la noción de literatura latinoamericana al tiempo que subvierten ese mismo ecosistema global del que forman parte. La segunda idea es que su internacionalización es facilitada por la clave vanguardista en que ambos autores conciben el arte. Son autores que retoman -de distintas maneras- la vanguardia histórica en el presente y que incluyen en varios de sus relatos una serie de referentes de ficción que nos remiten a la vanguardia artística de los años 1920-1930. Aun cuando faltan estos referentes, sigue presente el legado vanguardista a través de la fe en el procedimiento como elemento que distingue el arte de lo que no lo es y en el uso de recursos que desestabilizan el concepto tradicional de la literatura (manuscritos apócrifos, técnica de reapropiación de materiales preexistentes...). Su concepción de la traducción se sitúa en la misma línea: rechazan la modalidad de la traducción predominante en Occidente que postula la "invisibilidad" del traductor, según la célebre fórmula con la que Lawrence Venuti rebautizó el tradicional concepto de fidelidad, y tampoco creen en el carácter sagrado del original. Enfocan la traducción como potencialidad transformadora de la escritura, alternativa para reinventar el arte, espacio de innovación formal más que como operación de equivalencia.

\section{Traducciones y desplazamientos: Los ingrávidos de Valeria Luiselli}

Valeria Luiselli es una de las escritoras mexicanas más relevantes de los últimos años. Es autora de cinco libros muy diversos: el ensayo narrativo Papeles falsos 
(2010), las novelas Los ingrávidos (2011), Historia de mis dientes (2014) y Lost Children Archive (2019) y el ensayo-reportaje Los niños perdidos (2016). Su biografía casi la predestinaba a una carrera “global”. Luiselli nació en Ciudad de México en 1983. Hija de padres diplomáticos, antes de cumplir 18 años, ya había vivido en EEUU, Costa Rica, Corea del Sur, Sudáfrica e India. Regresó a México para estudiar en la UNAM y en 2011 se mudó a Nueva York para hacer el doctorado, ciudad donde sigue residiendo. Considera el español su lengua materna, aunque aprendió a leer y a escribir antes en inglés. Escribe alternando sus dos lenguas. Los tres primeros libros que ha publicado han sido escritos en español y luego traducidos al inglés, en estrecha colaboración con la traductora Christina MacSweeney, a la que Luiselli otorga una libertad creativa poco frecuente. Muchas veces los resultados de esta colaboración han producido cambios en el original en español, como se verá de manera más detenida abajo. Por su parte, Los niños perdidos está escrito originalmente en inglés y fue autotraducido por la autora al español, convirtiéndose parcialmente en otro texto. Y para la traducción al español de su última novela, Desierto sonoro, la escritora ha trabajado con Daniel Saldaña París. Luiselli ha publicado todos sus libros en español en la editorial independiente Sexto Piso (México/España), editorial de la que ya formó parte desde su fundación. Sus traducciones al inglés salen en Granta (Londres) y Coffee House Press (Minneapolis).

Los ingrávidos es un relato que emana de dos voces. La primera pertenece a una narradora que escribe sobre la vida cotidiana que lleva en Ciudad de México con su marido y sus dos hijos. Esta misma narradora configura simultáneamente una narración sobre la época en la que vivía en Nueva York y trabajaba como editora para un sello especializado en encontrar autores latinoamericanos no traducidos, que andaba febrilmente en busca del "próximo Bolaño”: “Trabajaba como dictaminadora y traductora en una editorial pequeña que se dedicaba a rescatar 'perlas extranjeras' que nadie compraba -porque al fin y al cabo estaban destinadas a una cultura insular donde la traducción se abomina por impura” (11). La otra voz pertenece a Gilberto Owen, poeta mexicano del grupo de los Contemporáneos. Como diplomático en EEUU en los tiempos del Harlem Renaissance, Owen hizo de mediador entre el mundo anglosajón y el hispanohablante desde su afán de divulgar la estética vanguardista. Durante su estancia en EEUU, la protagonista empieza a seguir obsesivamente los rastros de Owen en diferentes etapas de su vida: el joven que vive en Nueva York y el viejo cónsul en Filadelfia, alcohólico, que está a punto de morir. Owen se vuelve una fascinación para ella, incluso empieza a aparecérsele conforme avanza el texto. El nexo entre las dos historias es una traducción. Para interesar al jefe de la editorial donde trabaja, la narradora decide presentarle la falsa traducción de unos poemas de Owen hecha, supuestamente, por el fundador del objetivismo norteamericano, Louis Zukofsky. La historia desemboca en una estafa literaria: la 
narradora fabrica documentos apócrifos que su editor publica en la prensa. Finalmente, el fraude es desenmascarado y lleva a su dimisión y a su regreso a México. Pero la fijación de la joven mujer por Owen no se acaba allí. Muchos años después, resuelve escribir su biografía novelada a partir de retazos de su investigación, sugiriendo encuentros y amistades que pudieron ser posibles pero de los que no hay constancia.

La crítica ha dicho que la novela debe más a la poesía norteamericana que a la narrativa en español. Nueva York aparece como espacio de la vanguardia cultural: es allí donde Owen puede que hubiera coincidido con íconos del cosmopolitismo internacional de la era moderna: Federico García Lorca, José Limón, Homer Collyer y el ya nombrado Zukofsky, entre otros. Por otra parte, esta biografía imaginaria de Owen ha hecho resurgir el interés en EEUU por la poesía mexicana, suscitando una "Owenomanía"5. Puede decirse, entonces, que a Los ingrávidos se le puede aplicar la "refracción elíptica” de literatura nacional puesta como condición por Damrosch para ingresar en el circuito mundial: la obra sigue teniendo rasgos culturales de su origen mexicano. Muestra también que hay un México que se extiende más allá de las fronteras y que una buena parte de la literatura latinoamericana se produce desde hace tiempo en los EEUU, con frecuencia en español pero también en inglés.

En sus análisis, Walkowitz muestra que las obras "born translated” despliegan la traducción como tema o procedimiento o como vaivén entre lenguas al interior del texto. Sostiene que son novelas que incorporan la traducción al concebirse en diferentes lenguas y cuyos personajes se expresan en múltiples idiomas. El hecho de que hayan sido construidas pensando en el modo en que circularán a través del mundo en diferentes ediciones e idiomas tiene sus consecuencias para el proceso de traducción. A menudo estas novelas cambian de forma y significado cuando se mueven, generan algo nuevo, en una especie de textualidad expandida.

En efecto, Los ingrávidos ha crecido en otras lenguas. Fue traducido al inglés como Faces in the Crowd, título que hace suyo parte de un poema de catorce palabras de Ezra Pound. Pero quien compare las dos versiones notará que no hay un único original. Dice Luiselli a propósito: "There is a section in Faces in the Crowd, for instance, that my Italian translator, Elsa Tramontin, came up with. She produced such a good translation of it in Italian that I changed the original after her input, and so all the other translators followed her version instead of my 'original'” (Reber). Del mismo modo, en la versión en inglés, Luiselli y su traductora al

5 Véase al respecto la columna de Guillermo Sheridan en Letras Libres. 
inglés, Christina MacSweeney convierten al marido, que en Los ingrávidos es un director de cine, en un arquitecto. Otros cambios se deben a dificultades de tipo pragmático. Así, en inglés no aparece Zukovsky sino Zvorsky porque no fue posible conseguir los derechos para reproducir fragmentos de su emblemático poema "A", que se transforma entonces en "That”, una especie de paráfrasis. Por su parte, en Die Schwerelosen 6 , la traductora al alemán, Dagmar Ploetz, se adhiere a la versión inglesa en lo que respecta a Zukovsky, pero en cambio mantiene la profesión de cineasta para el marido. A veces hasta se agregan capítulos, como ha sido el caso de la edición en inglés de otra novela de Luiselli, La historia de mis dientes: a The Story of my Teeth se le añadió un capítulo titulado "The Chronologic", una especie de hoja de ruta para los lectores no familiarizados con la historia ni los referentes literarios mexicanos. Este capítulo fue escrito en su totalidad por MacSweeney, que también ha cambiado los nombres de los personajes y algunos acontecimientos. En una columna harto negativa sobre la recepción de la obra de Luiselli en México, el crítico Jorge Téllez lee esta cronología como una "normalización" del texto porque se adecúa a su público meta. Es una interpretación que parte de la premisa de la intocabilidad del original. Se podría aducir que, al adaptar la novela, Luiselli y su traductora insisten en que el mundo, antes que aparecer como un contenedor homogéneo en el que las obras literarias son "lo mismo" en varias lenguas, es un colectivo polifónico.

Es llamativo que Walkowitz apenas presta atención a la dimensión interlingüística de las traducciones como si, paradójicamente, estas obras de su corpus, que hablan extensamente del multilingüismo, no parecieran plantear importantes dificultades de traducción. Según Walkowitz, esto se debe a que la intraducibilidad de los textos "born translated" no reside en la presencia mimética de la(s) otra(s) lengua(s), sino en la narrativización de los procesos lingüísticos. O sea que no se trata aquí del tipo de intraducibilidad "habitual”, basada en la descripción lingüística - pensemos en el trabajo con ideolectos, particularismos, procedimientos como el cambio de código, juegos de palabras, términos en cursiva que denotan slang, palabras extranjeras, referencias locales etc. presente en autores como (para el ámbito latinoamericano) Cabrera Infante o Junot Díaz. Si hay "intraducibilidad" en los textos "born translated", se entiende en el sentido que Barbara Cassin otorgó al término en su Dictionnaire des intraduisibles, es decir, la traducción no

\footnotetext{
6 Agradezco a Andrea Pagni la información que me proporcionó sobre la traducción alemana de Los ingrávidos, cuando se debatió el tema durante el panel Contemporary Latin America: a Space for Translations del congreso de la American Comparative Literature Association en Utrecht, 6-9 de julio 2017.
} 
como lo que es irreductible en el original, sino como un proceso que nunca termina. Los "intraducibles" son para ella los síntomas de las diferencias entre los idiomas, por lo que nunca se puede dejar de traducir (3).

Aplicando esta idea a Los ingrávidos, cabe decir que no es, efectivamente, un texto que enfatice la particularidad de alguna variante del español, pero que sí evoca la interacción lingüística a través de la presencia diegética (y no tanto mimética). La otra lengua, que es el inglés, aparece reproducida en varias ocasiones bajo la forma de breves ejemplos de poesía citada (a la manera de los objets trouvés) y diferentes propuestas de traducción; por ejemplo, en la escena en la que se barajan diferentes opciones para los versos de San Juan de la Cruz (38-39). Sin embargo, la mayor parte del tiempo la novela lleva a su lector a reflexionar sobre el vaivén entre el español y el inglés que tiene lugar en Nueva York y en Ciudad de México a través de comentarios metalingüísticos como el siguiente: "A diferencia de la mayoría de los editores gringos, White no era monolingüe. Y a diferencia de la mayoría de los gringos que hablan español y han pasado una temporada larga o corta en Latinoamérica y creen que eso les da una especie de fogueo internacional tercermundista que los capacita intelectual y moralmente para -no sé muy bien para qué-, White sí entendía los mecanismos jodidos de la historia literaria latinoamericana" (36). O sobre el aprendizaje de la lengua de su bebé que nació en EEUU y ahora vive en México: "Produce sonidos que difícilmente se incorporarán al español, cuando lo aprenda a hablar. Vocales cerradas, opiniones guturales. Habla algo parecido a lo que hablan los personajes de los dramas de Lars von Trier” (26).

Se podría argumentar que Los ingrávidos presenta una estructura de quiasmo: el texto posee aquella misma traducibilidad que pone en tela de juicio. Se caracteriza por una tensión entre su ansia de plasmar un modus operandi multilingüe, que a fin de cuentas constituye la matriz de su pensamiento y de su afecto, y la necesidad de escribir en una sola lengua para poder publicar. Esta constelación explica por qué el "otro espacio" del texto manifiesto, o hipertexto, existe tan solo como proyección, como concepto, como aporía, como utopía. La otra lengua aparece como residuo que se plasma en escenas que dificultan u obstruyen esta transparencia, en nudos de opacidad. No es casual que se retomen aquí prácticas experimentales de la vanguardia, mecanismos productores de una nueva textualidad. Una de estas prácticas es la homofonía: el sonido de las palabras en inglés evoca acústicamente palabras en castellano similares, pero cuya semejanza fonética implica un desvío completo del sentido. Aparece cuando, en unas páginas muy elocuentes de Los ingrávidos, se narran las peripecias del grupo literario que se supone que Owen había fundado con García Lorca y Zukofsky. Zukofsky no habla español y los dos hispanohablantes hacen traducciones fonéticas de sus 
poemas que García Lorca lee en voz alta en los pasillos del metro. Este juego de transliteración conduce a interpretaciones disparatadas, como cuando el poema "A", que empieza con los versos "These, each in itself is saying, 'behoove us, / Disprove us least as things of love appearing" (108), es parafraseado por Owen como una oda a las aspiradoras Hoover ("These, itching and saying, 'behoover us / Dispose us least as things of love-happy-ring”, 116). En la performance de García Lorca, la traducción se vuelve aún más objeto de reflexión y de ironía, cuando estos mismos versos se transforman en "Aquí le pica y dice, 'hooveréanos, / Despáchanos mica como cosas del amor-alegre-anillo” (116).

Como queda dicho, esta estrategia de traducción puede identificarse como la homofonía. Se relaciona con lo que André Lefevere, tomando como ejemplo las versiones de Catulo en inglés firmadas precisamente por Celia y Louis Zukofsky (22), ha denominado “traducción fonética”, práctica que intenta reproducir en la lengua meta la configuración sonora del texto fuente y cuyo objetivo es crear imágenes nuevas. La homofonía desafía la noción tradicional de la traducción guiada por una idea de equivalencia con respecto a la lengua extranjera, ya que la reproducción es sustituida por una operación remodeladora y da lugar a un nuevo texto que no pretende funcionar como la traducción de un original, sino que se distancia de él. Son estas las escenas cuya traducción diverge considerablemente en las versiones en inglés, alemán, neerlandés, italiano... Algunos traductores continúan el juego fonético, mientras que otros restablecen la normalidad y traducen según el principio de la equivalencia.

Se puede concluir que, más que sacar a la superficie la idiosincrasia fonética/léxica/sintáctica de una lengua determinada, Luiselli muestra las operaciones lingüísticas subyacentes. Sin embargo, a su manera también logra visibilizar el proceso de traducción, la no evidencia de la fluidez, el fenómeno disruptivo de lo intraducible que, según la definición de Cassin, implica que su escritura arroje determinadas consecuencias para el proceso de traducción.

\section{Montajes transnacionales: Jacobo el mutante y Jacobo reloaded de Mario Bellatin}

\section{Jacobo el mutante}

Mario Bellatin es un autor mexicano-peruano, nacido en 1960, que se ha convertido en una de las voces imprescindibles de América Latina. Se perfila como un escritor neovanguardista cuya obra no obedece protocolos de representación o de causalidad, sino que desafía la idea de texto tradicional o de novela total 
latinoamericana ${ }^{7}$. Ha logrado crear un estilo tan lacónico que funciona como una marca. Viene ensayando una escritura modular, en la que cualquiera de sus textos puede replicarse en cualquier parte. La crítica recalca el carácter fragmentario de su escritura y el hecho de que sus libros rechazan toda categorización y rondan siempre otras artes. Salón de belleza (1994) es su novela corta más famosa. Su obra destaca por su prosa minuciosa, la densidad de sus imágenes y los universos inquietantes que evoca. Sus ejes temáticos son la culpa, la belleza, la muerte, la enfermedad y el dolor.

Bellatin se ha convertido en un escritor de culto. Hay un anecdotario alrededor de su figura que, de algún modo, da cuenta de cómo funciona su mundo narrativo que nunca concluye con la escritura, sino que se transforma en instalación, puesta en escena o engaño. Si Bellatin forja su mito personal de autor sobre una serie de hechos -haber nacido con un brazo malformado, pertenecer a una comunidad sufí, haber fundado la Escuela Dinámica de Escritores en el Distrito Federal, en la que se desaconsejaba escribir-, estos gestos extraliterarios no lo definen como un mero artista de happenings, sino que forman parte íntegra de su escritura.

En 2015 se desató una guerra en torno a Salón de belleza que ilustra el posicionamiento de Bellatin frente al mercado del libro. El autor prefiere diversificar su perfil: trabaja con numerosas editoriales, tanto grandes grupos transnacionales como sellos independientes y hasta artesanales y digitales. Como no cree en el concepto de texto definitivo, sus obras dan lugar a una proliferación de ediciones siempre modificadas. En 2015, Bellatin demandó a Planeta-Tusquets, una de las transnacionales literarias más poderosas del mundo, y lo hizo porque no le pagaban derechos de autor ni le permitían utilizar el texto que entonces ya tenía cinco reimpresiones. Habían firmado contrato en 1999 y, pese a su desacuerdo, la empresa lo renovó por otros quince años. Bellatin ganó la batalla y se convirtió en el primer autor a quien devuelven sus derechos ${ }^{8}$.

En 2002 salió una de sus obras más desconcertantes: Jacobo el mutante. Pretende ser la reescritura de una novela inédita del escritor austríaco Joseph Roth (1894-1939), autor de textos famosos como Radetzkymarsch (La marcha de Radetzky), que contiene la historia de una mutación. El tema central es el arte de la transformación. Los personajes se ubican en una serie de espacios en los que los cambios son incesantes y requieren, por tanto, una reflexión sobre la identidad y sobre la experiencia mística. La mutación se incluye desde el título como apuesta

7 Ha expresado sus ideas en el texto programático “Underwood portátil: modelo 1915” (Bellatin, Obra reunida 483-506).

8 Información encontrada en Mónica Felipe. 
a la metamorfosis. Sin embargo, el título ya entra en contradicción con el primer epígrafe que lo niega: "no se produjo ninguna mutación" (259). Existen varias ediciones del texto; trabajaré con la que fue publicada originalmente en México por Alfaguara y recogida posteriormente en Obra reunida (2013). Lleva fotografías de Ximenea Berecochea sobre las que volveré.

En Jacobo el mutante, un investigador literario poco fidedigno trata de reconstruir y analizar esa novela inédita de Roth, titulada Die Grenze (La Frontera), a partir de restos textuales. Narra la historia de Jacobo Pliniak, un rabino que es dueño de una taberna en el límite entre Rusia y Austria-Hungría cuyo nombre también es "La Frontera". Además de atender su negocio e iniciar en su fe a los niños de su comunidad, ayuda de manera semiclandestina a otros judíos de los pogromos rusos. Acosado por el antisemitismo, Jacobo tiene que salir de Polonia y se exilia en la costa oeste de EEUU. La historia experimenta un giro inesperado cuando, ya en el siglo XXI, Jacobo se transforma en una anciana octogenaria que lleva el mismo nombre que su propia hija adoptiva, Rosa Plinianson, una respetable anciana que lucha contra la instalación masiva de academias de baile en una ciudad de California?.

Las partes en cursiva son supuestas citas textuales de los fragmentos rescatados de la novela perdida. En realidad, Jacobo el mutante se presenta como el desvelamiento de un signo que permanece oculto, pues la novela se basa en la falsa recuperación de un texto de Roth, según ha confesado el propio Bellatin. Este texto citado, además, pretende ser una traducción hecha por el narrador, puesto que de la obra mencionada de Roth

[n]o se dispone aún de una traducción en regla, pero han aparecido fragmentos, como el ofrecido líneas antes, en revistas especializadas tanto de París como de la Costa oeste de los EEUU. En Frankfurt, la editorial Stroemfeld posee en sus archivos una antigua edición que se supone íntegra de la obra, y la editorial independiente Kieperheuer \& Witsh [sic] tiene otra versión que para muchos está compuesta sólo por una serie de fragmentos. Nadie sabe por qué, pero hasta ahora no se ha publicado ninguna de las dos. (262)

El texto posee, pues, un fuerte carácter metaficcional, al comentar la génesis de la literatura y de su circulación. Habla extensamente de los mediadores del texto: de la crítica inglesa que vivió con Roth los últimos años, de los lectores, de las dos versiones del manuscrito en manos de sendas editoriales, o sea, del libro como artefacto y de las problemáticas fronteras de lo que el canon entiende por

9 Lourdes Dávila (en untexto inédito que me fue facilitado por la autora) lee esta acumulación vacía de espacios para la danza como metáfora de una honda crisis de la producción cultural en nuestra época contemporánea. 
literatura. Roth no es de ningún modo un escritor desconocido aunque Bellatin, mediante su ficción, reavive el interés por los libros del mencionado escritor.

Según el narrador, algunos "errores" en la novela de Roth serían atribuibles a circunstancias externas: la larga duración de la creación; el hecho de que Roth solo trabajaba en este texto en sus frecuentes momentos de dependencia alcohólica (de allí las incoherencias); el carácter preparatorio del texto que no sería más que un borrador para otras obras; la pérdida de ciertos fragmentos. A estos residuos apócrifos se va superponiendo el relato del investigador literario que involucra elementos de la biografía de Roth, la tradición judía, su propia interpretación, el resultado de sus pesquisas en archivos, pasajes de la Biblia. Lo que leemos es, de hecho, una parodia a propósito de las fórmulas del discurso académico; una impostura de la erudición. Lo que está fuera del texto importa tanto o más de lo que se dice. A fin de cuentas, la obra puede ser leída como una elegía de un mundo destruido por el nazismo, ya que el drama del holocausto es el gran vacío alrededor del cual gira. Una lectura semejante confirma una de las premisas centrales de la obra de Bellatin, la que dice que la literatura no es referencial, sino que crea mundos paralelos que solo de manera oblicua se refieren a lo real.

Jacobo el mutante forma parte de una serie de obras de Bellatin producidas entre 2000 y 2002 que participan en una dinámica de construcciones apócrifas y atribuciones falsas, donde se privilegia el rol de la traducción. Shiki Nagaoka: una nariz de ficción es una biografía apócrifa en la que se instala la traducción como la dimensión más literaria de una obra. Por su parte, El jardín de la señora Murakami hace pasar al autor como el traductor de un texto inexistente. En Jacobo el mutante, además de un pseudotraductor, el narrador es un incompetente investigador literario. Las 33 fotografías de Ximena Berecochea insertadas en el texto de la novela pueden ser interpretadas erróneamente por el lector como traducciones intersemióticas. Miradas con detenimiento, resulta sin embargo que, por su carácter hermético y opaco, no son ilustraciones que revelan el sentido de la obra, sino que llevan a cabo otra mutación, esta vez de lo textual en lo visual. En lugar de reflejar el texto cuentan una segunda historia en la que aparecen, descontextualizadas, ciertas huellas de la presencia humana. Muestran restos de neumáticos en un camino de tierra reseca, botones entre la hierba, rocas en un paisaje de desierto, objetos hundidos en el agua de un lago.

\section{Jacob the Mutant: un remake}

La traducción es una noción clave para el universo narrativo de Bellatin. Muchas de sus obras son "born translated"; o sea, que la traducción se considera 
como un ingrediente necesario de la cadena de transformaciones en la que se apoya el proceso de escritura ya que, para Bellatin, una obra nunca está acabada y continúa desarrollándose cuando se vierte a otra lengua.

La obra de Bellatin ha sido traducida a varias lenguas, entre ellas al francés, al alemán y al inglés. Seis títulos han aparecido en inglés en editoriales independientes. Phoneme Media (Los Ángeles) ha publicado cuatro libros: El Gran Vidrio (The Large Glass), La mirada del pájaro transparente (The Transparent Bird's Gaze) y Nagaoka Shiki: una nariz de ficción (Shiki Nagaoka: a Nose for Fiction) -los tres traducidos por David Shook-, más el que se comentará abajo, Jacobo el mutante. Por su parte, Kurt Hollander tradujo Salón de belleza (Beauty Salon) para City Lights, un sello con sede en San Francisco.

Es particularmente relevante la mutación que sufrió Jacobo el mutante durante el proceso de traducción, mutación que afectó al texto original. Cuando el traductor al inglés y judío ortodoxo Jacobo Steinberg estaba trabajando con el texto, mandó una carta al autor contándole que había descubierto partes reales; a esa carta contestó Bellatin con una explicación en la que un narrador llamado Mario Bellatin recuerda a su abuelo judío y reflexiona sobre su propia conversión al sufismo. Ese comentario terminó siendo tan largo que llevó a reescribir el original y a publicar una versión reelaborada y expandida, Jacobo reloaded (Sexto Piso, 2014) ${ }^{10}$. Jacobo reloaded comienza de la misma manera que Jacobo el mutante: nos reconduce a La Frontera de Roth, pero a partir de este inicio falso Bellatin introduce personajes latinoamericanos, entre los cuales está su abuelo. Más en particular, retoma fragmentos enteros de un texto suyo anterior, Lecciones para una liebre muerta $(2005)^{11}$, que también trata de los recuerdos que un personaje narrador, converso islámico del judaísmo, tiene de su abuelo, que padeció el rechazo social de su lengua quechua. La vida del propio Bellatin, que evoca en Jacobo reloaded, tiene, como la de Roth, un importante "no dicho" aludido elípticamente: es una vida heredera de una lengua proscrita, esta vez el yiddish, que ahora se ha desplazado al Perú de su infancia. En ambos casos, observamos la ausencia de una lengua perdida que retorna constantemente de modo espectral. En su "Nota del Autor", Bellatin remite a este sustrato original desaparecido: "Las posibles contradicciones presentes en el texto anterior pueden haber sido consecuencias de que éste originalmente no fue concebido en el idioma en el que se encuentra plasmado" (81). Este epígrafe, que encabezaba una protoversión de Lecciones para una liebre muerta, titulada "Quechua", pero que había desaparecido de la novela

10 Véase Armento.

11 Texto que a su vez amplía el relato "Quechua”, como ha mostrado Juan Pablo Cuartas en su artículo de crítica genética. 
de 2005 (Cuartas), vuelve a aparecer literalmente en Jacobo reloaded, repitiéndose así un motivo presente en libros anteriores. En su estudio de la danza en Jacobo reloaded, Lourdes Dávila explica que en esta versión ampliada, la expulsión del cuerpo judío del espacio de lo social ya no se remonta a los pogromos rusos, sino a una época anterior, es decir, a la Venecia del siglo XV. Según Dávila, que ha tenido acceso al archivo que Bellatin ha utilizado explícita o implícitamente para la secuela, "[e]s allí donde observa el narrador el germen legal de la prohibición de la danza en los espacios públicos junto con la prohibición de las escuelas de baile o canto judío como forma de regular, controlar y criminalizar la expansión del judaísmo" (8). Este archivo, de donde proviene la mayor parte de las referencias a los bailes judíos que aparecen en Jacobo reloaded, fue creado por Jacob Steinberg, que por lo tanto debe ser considerado coautor de la novela.

La traducción al inglés que finalmente publicó Steinberg, Jacob the Mutant, es de la secuela, no del original. Contiene los paratextos de Jacobo reloaded: "Could There Have Been a Reason for Writing Jacob the Mutant”; "Affairs with Respect to Jacobo reloaded that It Would Be Good Not to Forget”, incluido el epílogo del traductor titulado "The Diary of Rose Eigen: A Translator's Afterword”, que no es lo que se espera de este tipo de texto, sino un testimonio personal en el que el traductor relaciona la novela con su propia vida, declarando que él también vivió una mutación parecida a la de Jacobo Pliniak. En Jacobo reloaded, las ilustraciones de la mexicana Ximena Berecochea han sido reemplazadas por los dibujos de la húngara Zsu Szkurka (que faltan en la traducción; solo han sido reproducidos dos mapas explicativos de la dibujante), que contrariamente a las fotos de Berecochea complementan la historia y ahondan en ella. Cabe decir, entonces, que, del mismo modo en que Jacobo el mutante es presentado como una traducción de un texto perdido de Roth, Jacob the Mutant es una traducción que lleva la propuesta estética de Bellatin a sus últimas consecuencias.

\section{Conclusión}

En lo que precede, he presentado dos novelas latinoamericanas que, según los criterios de Rebecca Walkowitz, nacieron “ya traducidas”. Son textos que no aparecen simplemente en traducción, sino que han sido escritos para ser traducidos, conteniendo la traducción en su génesis. El carácter translaticio de estas obras se prolonga en sus traducciones, lo que se manifiesta en algunos cambios notables en las traducciones al inglés y al alemán de Los ingrávidos y en la traducción sui géneris al inglés de Jacobo el mutante, que, de hecho, consiste en una reescritura desencadenada por la reacción del traductor al original. 
Por otra parte, de lo anteriormente expuesto se desprende que este tipo de textos no necesariamente deben confirmar el horizonte de expectativas del mercado ni llevar a una literatura global desmemoriada. Tanto Los ingrávidos como Jacobo el mutante/Jacobo reloaded confrontan a su manera la estandarización cultural propuesta por la globalización. Son obras que participan en distintas culturas literarias a la vez: la estadounidense y la mexicana en el caso de Luiselli, y la europea y peruana en el de Bellatin. Esta doble pertenencia explica su mayor circulación, el factor sine qua non de la literatura mundial, aunque hay que reconocer que el hecho de trascender el medio local para entrar en el escenario global no constituye un mérito literario en sí y que existen también muchas formas ultralocales de lo contemporáneo que no podrían ni tendrían por qué formar parte de este corpus.

Si estos dos autores escapan a los parámetros comerciales impuestos por la cultura global y logran integrarse en ella de manera original, poniendo de relieve elementos de la cultura latinoamericana, esto se debe en parte a su apuesta por una literatura que trabaja con el legado de la vanguardia (Luiselli) o, directamente, con los principios de la literatura experimental (Bellatin). Luiselli retrocede hasta principios del siglo XX para convertir en personajes a algunas figuras de la modernidad mexicana, mientras que Bellatin convoca el imaginario del exilio judío para asociarlo, a través de un ingenioso montaje, con la marginalización del yiddish en el Perú. Aunque cabría preguntarse en este contexto si ambos autores no "copian" de manera inteligente ciertos conceptos que han probado su éxito internacional: Luiselli el modelo Detectives salvajes, usando las vanguardias como ancla de una lectura "globalizada"; Bellatin el "modelo judío" que también un autor como Eduardo Halfon a estas alturas ha "usado" para generar un éxito internacional considerable ${ }^{12}$. En Luiselli la traducción aparece por doquier, pero funciona más como un tropo que como una práctica vinculada a la especificidad de una lengua determinada. Bellatin, que quiere purgar sus textos de todo origen, maneja un estilo deliberadamente neutro y, por tanto, eminentemente traducible. Vuelve a la vanguardia para tensar la relación entre la escritura y la circulación del texto en el mercado editorial. En los dos casos, las historias, independientemente del aspecto lingüístico, siguen siendo narrables para una audiencia de monolingües cosmopolitas.

El resultado de estas operaciones es que ya nada se considera local porque no hay extranjería y nada está al margen porque no hay centro. De acuerdo con la tesis defendida por Héctor Hoyos en Beyond Bolaño (en cuyo último capítulo, "Duchamp and Beuys as Latin American Writers", se aborda la obra de Bellatin)

12 Debo este comentario a Benjamin Loy. 
estos autores buscan claves para entender la forma en que la literatura latinoamericana representa al mundo globalizado y se ve representada en él. Hoyos apuesta por una multipolaridad en el campo cultural, en la que la noción de novela global latinoamericana sería un polo constitutivo. Los proyectos de Luiselli y de Bellatin contribuyen activamente a descentrar ciertos imaginarios y a colocar en el centro otros. Sin embargo, es legítimo preguntarse si, a la larga, la experimentación en la que se apoyan no corre el riesgo de terminar ofreciendo una propuesta estandarizada en sí misma. Sea como fuere, los dos estudios de caso dejan bien a las claras que usar el paradigma de la literatura mundial resulta provechoso, ya que la producción latinoamericana está irremediable y plenamente inscrita en los flujos transnacionales.

\section{Bibliografía}

Armenta, Carlos. “Jacobo reloaded, nuevo libro de Mario Bellatin”. El informador, 03/12/2014. www.informador.mx/Cultura/Jacobo-Reloaded-nuevo-libro-de-Mario-Bellatin-201412030061.html, consultado 6 de mayo 2018.

Bellatin, Mario. Jacob the Mutant. Trad. Jacob Steinberg. Phoneme Media, 2015.

--.. Jacobo reloaded. Sexto Piso, 2014.

--.. Jacobo el mutante. En: Obra reunida. Alfaguara, 2013 [2002], pp. 257-290.

--.. Obra reunida. Alfaguara, 2013.

Cassin, Barbara. Le vocabulaire européen des philosophies: Dictionnaire des intraduisibles. Du Seuil/Le Robert, 2004.

Cuartas, Juan Pablo. "Mario Bellatin, ¿Qué clase de espanto puede generar una escritura semejante?”. VI Jornadas Internacionales de Filología y Lingüística. I Jornada de Crítica Genética "Las lenguas del archivo". Universidad Nacional de La Plata, 2013. sedici.unlp. edu.ar/bitstream/handle/10915/42252/Documento_completo.pdf?sequence=1, consultado 5 de mayo 2018.

Damrosch, David. What Is World Literature? Princeton University Press, 2003.

Dávila, Lourdes. "Jacobo Reloaded: El movimiento hacia el fin de la cultura”. Ponencia inédita leída en el IXL Congreso IILI 2018, Pontificia Universidad Javeriana de Bogotá, 13 junio 2018.

Hoyos, Héctor. Beyond Bolaño: The Global Latin American Novel. Columbia University Press, 2015.

Lefevere, André. Translating Poetry: Seven Strategies and a Blueprint. Van Gorcum, 1975.

Lennon, Brian. In Babel's Shadow. Multilingual Literatures, Monolingual States. University of Minnesota Press, 2010.

Luiselli, Valeria. The Story of My Teeth. Trad. Christina MacSweeney. Coffee House Press, 2015 [2015].

--.. Faces in the Crowd. Trad. Christina MacSweeney. Coffee House Press, 2014 [2012].

---. La historia de mis dientes. Sexto Piso, 2013.

---. Die Schwerelosen. Trad. Dagmar Ploetz. Verlag Antje Kunstmann, 2013.

---. Los ingrávidos. Sexto Piso, 2011. 
Mónaco Felipe, Paula. “Mario Bellatin, perruno y enfermo de varios malos”. Cartón Piedra, 06/02/2017. www.cartonpiedra.com.ec/noticias/edicion-n-275/1/mario-bellatin-perruno -y-enfermo-de-varios-males, consultado 6 de mayo 2018.

Mora, Vicente Luis. “Globalización y literaturas hispánicas: de lo posnacional a la novela glocal”. Pasavento, vol 2, no 2, 2014. www.pasavento.com/pdf/04_05_mora.pdf, consultado 28 de abril 2018.

Parks, Tim. Where l'm Reading From: the Changing World of Books. Harvill Secker, 2014.

Reber, Nichole. "Writing Yourself into the World. A Conversation with Valeria Luiselli”. World Literature Today 90, 01/01/2016. www.worldliteraturetoday.org/2016/january/writingyourself-world-conversation-valeria-luiselli-nichole-l-reber, consultado 7 de abril 2018.

Sánchez Prado, Ignacio M. (ed.). América Latina en la "literatura mundial”. IILI, 2006.

Sheridan, Guillermo. “Nuevos mensajes de Gilberto". Letras Libres, 07/10/2012. www.letrasli bres.com/mexico-espana/nuevos-mensajes-gilberto, consultado 7 de mayo 2018.

Téllez, Jorge. "La otra historia de mis dientes". Letras Libres, 19/02/2016. www.letraslibres. com/mexico-espana/la-otra-historia-mis-dientes, consultado 7 de mayo 2018.

Walkowitz, Rebecca L. Born Translated. The Contemporary Novel in an Age of World Literature. Columbia University Press, 2015. 